\title{
Annual impact of scribes on physician productivity and revenue in a cardiology clinic
}

This article was published in the following Dove Press journal:

ClinicoEconomics and Outcomes Research

30 September 2015

Number of times this article has been viewed

\section{Alan J Bank \\ Ryan M Gage}

United Heart and Vascular Clinic, St Paul, MN, USA
Correspondence: Alan J Bank United Heart and Vascular Clinic, 225 North Smith Avenue Suite 400, St Paul, MN 55I02, USA

$\mathrm{Tel}+\mid$ 65। 24l 2815

Fax + 65I 24I 28I8

Email Alan.Bank@allina.com
Objective: Scribes are increasingly being used in clinics to assist physicians with documentation during patient care. The annual effect of scribes in a real-world clinic on physician productivity and revenue has not been evaluated.

Methods: We performed a retrospective study comparing the productivity during routine clinic visits of ten cardiologists using scribes vs 15 cardiologists without scribes. We tracked patients per hour and patients per year seen per physician. Average direct revenue (clinic visit) and downstream revenue (cardiovascular revenue in the 2 months following a clinic visit) were measured in 486 patients and used to calculate annual revenue generated as a result of increased productivity.

Results: Physicians with scribes saw 955 new and 4,830 follow-up patients vs 1,318 new and 7,150 follow-up patients seen by physicians without scribes. Physicians with scribes saw $9.6 \%$ more patients per hour $(2.50 \pm 0.27$ vs $2.28 \pm 0.15, P<0.001)$. This improved productivity resulted in 84 additional new and 423 additional follow-up patients seen, 3,029 additional work relative value units (wRVUs) generated, and an increased cardiovascular revenue of $\$ 1,348,437$. Physicians with scribes also generated an additional revenue of $\$ 24,257$ by producing clinic notes that were coded at a higher level. Total additional revenue generated was $\$ 1,372,694$ at a cost of $\$ 98,588$ for the scribes.

Conclusion: Physician productivity in a cardiology clinic was $\sim 10 \%$ higher for physicians using scribes. This improved productivity resulted in 84 additional new and 423 additional follow-up patients seen in 1 year. The use of scribes resulted in the generation of 3,029 additional wRVUs and an additional annual revenue of $\$ 1,372,694$ at a cost of $\$ 98,588$.

Keywords: physician productivity, medical economics, scribe

\section{Introduction}

Physician productivity is an important and understudied component of health care in the US and across the world. Physician productivity critically affects many aspects of health care including patient access to care, ${ }^{1}$ cost of care, physician ${ }^{2}$ and patient ${ }^{3}$ satisfaction, quality of care, and physician reimbursement. ${ }^{4}$ Many factors are potentially adversely affecting physician productivity including increased use of electronic medical records (EMRs), ${ }^{5,6}$ increased paperwork, ${ }^{7,8}$ increased medical bureaucracy and regulation, ${ }^{9}$ physician burnout, ${ }^{2,10,11}$ and increased volume of data available per patient. Strategies used to improve physician productivity (and reduce costs) include the use of physician extenders (nurse practitioners, physician assistants, among others) and the implementation of clinical pathways. ${ }^{12-15}$ An additional strategy to improve physician productivity is the use of medical scribes. Medical scribes are trained assistants who perform 
multiple documentation tasks under physician supervision to assist physicians during their care of patients. Although scribes have been involved in medical care in emergency rooms (ERs) for well over a decade, they are infrequently used in the clinic setting. In addition, there are little data on the effects of scribes on physician productivity and revenue in the clinic (or other settings). A study performed in the ER demonstrated that the use of scribes increased patients seen per hour by 0.8 , and work relative value units (wRVUs) generated per hour by $2.4 .{ }^{16}$ We previously performed a prospective, controlled, pilot study involving four physicians working 130 clinic hours that demonstrated large improvements in physician productivity and revenue generation in a cardiology clinic. ${ }^{1}$ To our knowledge, there are no studies that have assessed the effect of scribes on physician productivity or revenue generation over a prolonged period of time in a real-world clinic setting. In 2014, ten physicians in our clinic used scribes for their routine outpatient visits at our main office, whereas 15 did not. We performed a retrospective analysis of physician productivity and revenue generation in these two groups of physicians, hypothesizing that the utilization of scribes would allow for an increase in patient volume resulting in increased direct and downstream revenue over a 1 -year period in a real-world clinic setting.

\section{Methods}

\section{Cardiology clinic and EMR}

This study was performed at the main office of United Heart and Vascular Clinic (UHVC) during 2014. UHVC is a cardiology group in St Paul, MN, owned by a large health care organization, Allina Health. There are 15 general cardiologists, six interventional cardiologists, and four electrophysiologists. UHVC physicians use an integrated EMR (Epic Systems Corporation, Verona, WI, USA) for all inpatient and outpatient medical care.

\section{Scribes}

Emergency Care Consultants provided medical scribe services. A total of 16 scribes assisted the ten cardiologists who used scribes. Scribes were often paired with specific physicians, but each physician worked with several different scribes over the course of a year. All scribes underwent training in the use of our EMR, clinic procedures, adhering to the Health Insurance Portability and Accountability Act and other regulations related to medical care, and medical and cardiology terminology. Scribe training is detailed in Table 1 and totaled 184 hours per scribe. Tasks performed by the scribes in our clinic have been detailed previously. ${ }^{1}$
Table I Scribe training

\begin{tabular}{lll}
\hline & Training task & $\begin{array}{l}\text { Number } \\
\text { of Hours }\end{array}$ \\
\hline General & Review of medical terminology & 4 \\
medicine & Classroom lecture on major diagnoses & 4 \\
& On-floor training & 64 \\
& Supervised scribing & 80 \\
& Review of notes with supervisor & 2 \\
& Quarterly meeting with supervisor & 2 \\
& Annual review of work & 2 \\
Cardiology & Review of terminology & 2 \\
specific & Review of cardiology template with physician & 1 \\
& Review of clinic processes & 1 \\
& Shadowing scribe & 20 \\
Total & Review guide of common cardiology diagnoses & 2 \\
\hline
\end{tabular}

Briefly, scribes reviewed charts prior to clinic visits, generated preliminary notes using a template provided by each physician, recorded historical information during clinic visits, transcribed information provided by the physician after clinic visits, and completed scheduling, billing, patient instruction, and after-visit summary forms under the direction of the physician.

This study was performed in accordance with national regulations and was deemed exempt from human subjects institutional review board approval.

\section{Physician productivity}

All patient clinic visits at our main office were tracked during 2014. Patients seen at outreach sites, in device clinic, or in our urgent care clinic were not included as we did not usually use scribes for those visits. For physicians without scribes, patients were scheduled at 20 minutes for follow-up and 40 minutes for new patient visits. Every 4 hours, one followup slot was left unscheduled for physicians to "catch up" with dictation/documentation. This open 20-minute slot has been part of our standard clinic practice because when we began using an EMR in 2011, physicians were unable to see patients at a pace of one every 20 minutes without falling far behind in their visits. This scheduling template results in 22 patients (new patients counted as two) scheduled for a full 8-hour clinic day. For physicians using scribes, the open 20-minute slot every 4 hours was eliminated resulting in 24 patients scheduled for a full 8-hour clinic day ( $9 \%$ increase in patient slots). One physician with the most experience using scribes had a template with 28 patient slots available ( $27 \%$ increase in patient slots). No slots were intentionally left unscheduled. The average percentage of office slots filled monthly in our clinic for 2014 was $87.7 \%$ (range $82.2 \%-91.9 \%$ ). We routinely have a large backlog of patients who are unable to 
be seen for follow-up within the time frame requested by their physician.

Productivity was measured during a 3-month period for all physicians at the clinic. Patients seen during this period and number of hours scheduled for these visits were tracked. Physician productivity was defined as the number of patients seen per hour of clinic. wRVUs, a standard measure of physician work, were also tracked. Additional wRVUs generated were calculated as the number of additional new and follow-up patients seen as a result of increased physician productivity multiplied by the average total (direct and downstream) wRVUs generated per new and follow-up patient.

\section{Financial measurements}

The impact of scribes on annual cardiovascular (CV) revenue was calculated as the number of additional new and follow-up patients seen as a result of increased physician productivity multiplied by the average total (direct and downstream) revenue generated per new and follow-up patient. The annual number of additional patients seen was calculated as the difference between the actual number of patients seen by the physicians with scribes and the estimated number of patients seen by physicians with scribes, had their productivity been the same as that of the physicians without scribes.

In order to determine the average revenue generated by a new and follow-up patient, we randomly selected approximately four new and 16 follow-up patients seen in clinic by each physician. We calculated the revenue generated by each patient as the charges billed $\times 0.48$ for clinic visits and $\times 0.33$ for downstream revenue. These numbers are based on the average collection percentage for $\mathrm{CV}$ services at our health care system. We tracked the revenue generated by each patient and separated it into different categories. Direct clinic revenue was defined as the revenue generated from the clinic visit. Downstream revenue was defined as all $\mathrm{CV}$ revenue generated in the 2 months following each clinic visit. Downstream revenue was separated into three categories: professional services revenue (physician billing for inpatient visits, tests, and procedures), outpatient revenue (technical revenue for outpatient tests and procedures), and hospital inpatient revenue. The average revenue for new and follow-up patients was calculated and used to determine the annual revenue generated as a result of increased physician productivity. The cost of using scribes was $\$ 25$ per hour which included time preparing the charts prior to patient visits, participating in the clinic visits, and completing documentation after visits. All costs within this present study were measured in US dollars.
Physicians assigned a level of service for each new patient and follow-up visit based on standard coding and billing procedures. All physicians underwent at least 4 hours of training in appropriate coding procedures in 2014. All clinic notes were reviewed by billing specialists at our clinic, and the level of service was modified from that assigned by the physician if the documentation did not justify the level of service chosen. The additional revenue generated as a result of higher average coded and billed level of service by the physicians using scribes was calculated as the revenue generated from clinic visits by these physicians minus the revenue that would have been generated if the physicians with scribes billed identical to the physicians without scribes.

\section{Statistics}

Productivity measures and other data were calculated and reported as mean \pm standard deviation. The comparison of continuous variables between physicians with and without scribes was made using unpaired Student's $t$-tests. The Fischer's exact test was used to test the difference in coding level distribution between physicians with and without scribes. Two-sided $P$-values $<0.05$ were considered significant.

\section{Results}

Ten out of 25 physicians chose to use scribes in our clinic. Out of these ten physicians, five were general cardiologists, two were interventionalists, and three were electrophysiologists. Out of the 15 physicians not using scribes, ten were general cardiologists, four were interventionalists, and one was an electrophysiologist. Cardiologists in our clinic saw 4,713 new patients and 18,820 follow-up patients in 2014. Of these, 2,440 (51.8\%) new and 6,840 (36.3\%) follow-up patients were seen in outreach clinic, device clinic, or urgent care clinic where scribes were not used. The remaining 2,273 new patients and 11,980 follow-up patients were seen in our main office and comprised the study population. Table 2 shows the number of new and follow-up patients seen in 2014 by physicians in our main office with and without scribes, and the productivity of physicians in each group. Physicians with scribes saw 955 (16.5\%) new patients and 4,830 (83.5\%) follow-up patients. Physicians without scribes saw 1,318 (15.6\%) new patients and 7,150 (84.4\%) follow-up patients. Figure 1 shows the productivity of each physician. The five most productive physicians used scribes. Physicians with scribes saw $9.6 \%$ more patients per hour $(2.50 \pm 0.27$ vs $2.28 \pm 0.15$, $P=0.01)$ than those without scribes. If the physicians with scribes had productivity similar to those without scribes 
Table 2 Physician patient volumes and productivity in 2014

\begin{tabular}{lll}
\hline & $\begin{array}{l}\text { Physicians with } \\
\text { scribes (10) }\end{array}$ & $\begin{array}{l}\text { Physicians without } \\
\text { scribes (15) }\end{array}$ \\
\hline New patients $(\mathrm{n})$ & 955 & 1,318 \\
Follow-up patients $(\mathrm{n})$ & 4,830 & 7,150 \\
Total patients $(\mathrm{n})$ & 5,785 & 8,468 \\
Patients per hour & $2.50 \pm 0.27^{*}$ & $2.28 \pm 0.15$
\end{tabular}

Note: $* P=0.0$ I. Data are presented as mean \pm standard deviation.

(2.28 patients per hour), they would have seen 84 less new patients and 423 less follow-up patients.

The ten physicians using scribes were asked to estimate the number of additional hours of work needed on an average clinic day to see the same number of patients and complete all documentation, had they not had scribes. These physicians estimated that scribes saved them $2.5 \pm 0.9$ (range 1.25-4.0) hours daily.

Revenue was tracked on 94 new patients and 392 follow-up patients. Table 3 shows the direct, downstream, and total revenue for the average new and follow-up patient. The total revenue for a new patient was $\$ 4,939$ and for a follow-up patient was $\$ 2,207$, with most of the revenue generated downstream and not from the initial clinic visit. The 84 additional new patients seen as a result of the $9.6 \%$ increased productivity using scribes resulted in an additional revenue of $\$ 414,876$. The additional 423 follow-up patients seen resulted in an additional revenue of $\$ 933,561$. The total additional revenue attributed to the nearly $10 \%$ increase in productivity from using scribes was $\$ 1,348,437$.

The average direct (clinic visit) and downstream wRVUs generated for a new patient were 3.64 and 7.14, respectively. These average values for a follow-up patient were 1.75 and 3.27 , respectively. The additional annual wRVUs generated as a result of the $9.6 \%$ increased productivity from using scribes was 3,029.
Table 4 shows the percentage of new and follow-up patients seen with and without scribes who were billed at various levels of care. The level of coding varied significantly ( $P<0.001$ for new patients, $P=0.017$ for follow-up patients) between physicians using scribes and those who did not. In particular, the number of new and follow-up patients coded at the highest level was higher for the physicians with scribes. The higher level of service coded and billed by these physicians resulted in an additional \$24,257 in annual revenue. The total additional revenue attributed to both increased productivity and higher billing level for the physicians using scribes was $\$ 1,372,694$. This additional revenue accrued at a cost of $\$ 98,588$ for the scribes.

\section{Discussion}

This study demonstrates that using scribes in a large cardiology clinic as part of routine clinical care results in a nearly $10 \%$ increase in productivity and a modest increase in level of service billed. The use of scribes resulted in an increase of $\$ 1,348,437$ in annual $\mathrm{CV}$ revenue and 3,029 additional wRVUs from increased productivity, and \$24,257 from improved documentation and higher billed level of service. This additional revenue was generated at a cost for the scribes of $\$ 98,588$.

\section{Physician productivity}

As EMRs are increasingly being used in the US, concerns about their effects on physician productivity have been raised. A common concern is that productivity is reduced significantly during the transition to an EMR. ${ }^{17}$ More importantly, the ongoing effects of EMRs on physician productivity in the clinic setting are unclear, with studies showing mixed results. ${ }^{6,18-22}$ In one study, emergency department physicians spent $44 \%$ of their time on data entry and only $28 \%$ on direct patient contact. ${ }^{4}$ This data entry into an EMR required

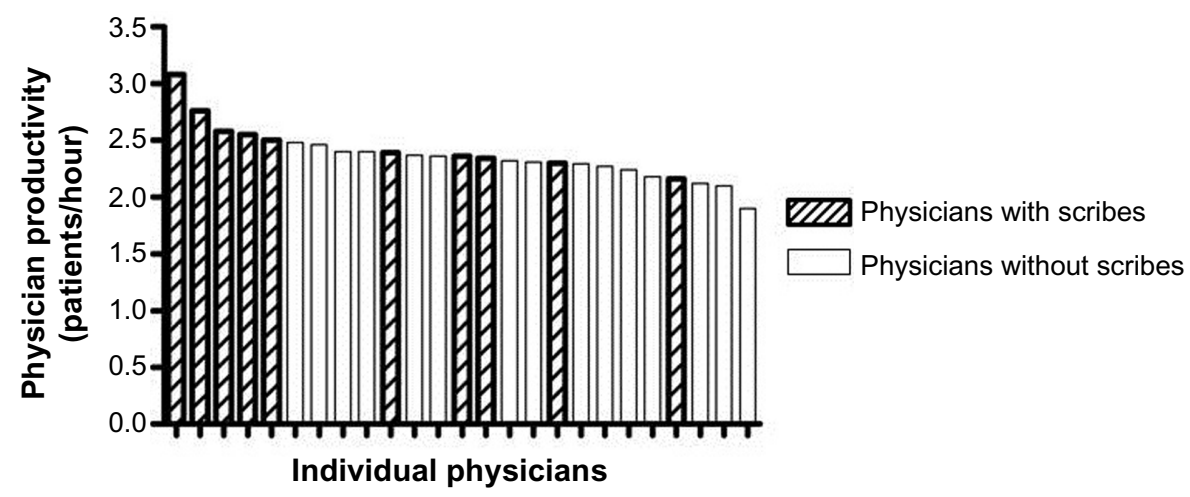

Figure I Physician productivity.

Note: Individual productivity (patients seen/hour) of physicians with and without scribes. 
Table 3 Average cardiovascular revenue generated per clinic patient

\begin{tabular}{|c|c|c|c|c|c|}
\hline & \multirow{2}{*}{$\begin{array}{l}\text { Direct } \\
\text { Clinic } \\
\text { visit }\end{array}$} & \multicolumn{3}{|l|}{ Downstream } & \multirow[t]{2}{*}{ Total } \\
\hline & & $\begin{array}{l}\text { Professional } \\
\text { services }\end{array}$ & $\begin{array}{l}\text { Outpatient } \\
\text { technical }\end{array}$ & Hospital & \\
\hline $\begin{array}{l}\text { New } \\
\text { patient }\end{array}$ & $\$ 209$ & $\$ 380$ & $\$ 3,418$ & $\$ 932$ & $\$ 4,939$ \\
\hline $\begin{array}{l}\text { Follow-up } \\
\text { patient }\end{array}$ & $\$ 117$ & $\$ 172$ & $\$ 942$ & $\$ 976$ & $\$ 2,207$ \\
\hline
\end{tabular}

320-400 mouse clicks per hour. In the present study, we demonstrate that physicians using scribes saw $9.6 \%$ more patients per hour than those not using scribes. This improvement in productivity was a result of these physicians having $\sim 10 \%$ more patients scheduled per hour than those physicians not using scribes. This was likely a true increase in productivity and not simply a result of differing scheduling templates because the physicians not using scribes were unable and unwilling to see patients using the scheduling template used for physicians with scribes. In addition, the physicians using scribes finished most or all of their work during the allotted 8 hours of clinic and did not require significant additional time to complete documentation after standard working hours. Although a nearly $10 \%$ increase in productivity is what was seen by the patients (with respect to access) and the health care system (with respect to patient throughput), the true increase in productivity from the physician perspective was much greater. Physicians estimated that the scribes saved them 2.5 hours per day by reducing time required between visits, during lunch breaks, and in the evening, to complete documentation. Thus, the physicians were seeing $10 \%$ more patients in $\sim 8$ hours of scheduled clinic time, in addition to working $\sim 24 \%$ less $(2.5$ hours less out of an estimated 10.5 hours required to complete their work without scribes). An improvement in productivity of this magnitude is consistent with our previous finding from a time-motion study that demonstrated that total time to complete a followup patient visit (including time before, during, and after the visit) decreased by $36 \%$, from 25 minutes to 16 minutes. ${ }^{1}$ The improvement in productivity is less than the $59 \%$ increase

Table 4 Coding level for patient visits with and without scribes

\begin{tabular}{llllll}
\hline & & Level 2 & Level 3 & Level 4 & Level 5 \\
\hline New patient & No scribe & $0.9 \%$ & $11.5 \%$ & $62.2 \%$ & $25.4 \%$ \\
& Scribe* & $0.6 \%$ & $3.4 \%$ & $50.7 \%$ & $45.3 \%$ \\
Follow-up patient & No scribe & $0.6 \%$ & $18.8 \%$ & $72.6 \%$ & $8.0 \%$ \\
& Scribe** & $0.7 \%$ & $16.3 \%$ & $71.0 \%$ & $12.0 \%$ \\
\hline
\end{tabular}

Notes: ${ }^{*} P<0.001$, comparing distribution between scribe and no scribe usage within new patients. $* * P=0.017$, comparing distribution between scribe and no scribe usage within follow-up patients. we demonstrated in our previous pilot study. ${ }^{1}$ We have chosen a less aggressive scheduling template for our real-world use of scribes than we used in our pilot study because physicians felt that they were too rushed using the previous scheduling template. Our findings are also consistent with those found in a study of ER physicians using scribes, where productivity increased by $\sim 32 \%$ ( 0.8 additional patients per hour seen above a baseline of 2.5 patients per hour).${ }^{16}$ The impact of this improved productivity on patient access to care is apparent, as our clinic did not have the capacity to see these additional patients without either the use of scribes (or other measures) to increase productivity or an increase in the supply of physicians available to see patients in clinic.

Increasing physician productivity by $9.6 \%$ resulted in 84 additional new patient and 423 additional follow-up patient visits during 2014. These numbers vastly underestimate the potential impact of scribes on clinic volumes (and revenue). Patient visits with scribes only comprised $25.7 \%$ of all follow-up visits and $20.3 \%$ of all new patient visits because 15 physicians did not use scribes and because we did not use scribes for our outreach, urgent care, or device clinic visits. Had scribes been used for all clinic visits by all physicians, the number of additional patients seen and the associated revenue generated annually would have been four- to fivefold higher.

\section{Billing and coding}

We demonstrate that patient visits with a scribe were coded and billed at a higher level than those without a scribe. Although the financial impact of this was relatively small, the impact on quality of care and/or on liability may not be and was not assessed in this study. The higher level of service associated with visits using a scribe suggests that documentation may be better during those visits. Although we did not quantify the quality or quantity of documentation, we routinely have all clinic notes evaluated by coding specialists who verify that the level of service chosen by the physician is justified based on the documentation.

\section{Revenue and cost}

The use of scribes had a large effect on CV revenue generated by the health care system, predominantly through increased physician productivity. Although patient visits with scribes were coded at a higher level than those without scribes (presumably due to better documentation), the financial impact was only $\sim \$ 24,257$ of increased revenue per year. In contrast, the effect of increased productivity on revenue was $>55$ times as high at $\$ 1,348,437$ per year. 
Several factors should be taken into consideration when determining the financial value of using scribes that can make the $\sim 14: 1$ return on investment higher or lower. First, the cost of the scribes is similar to the cost of medical transcription, so for physicians who dictate their notes, the transition to using scribes is probably cost neutral. Second, there are some costs to generating the additional revenue as a result of increased productivity. These could include the need for increased space, computers, or personnel to accommodate the nearly $10 \%$ increase in patient flow through the clinic. Finally, there are direct costs associated with the additional revenue generated such as supply costs for performing additional procedures. We did not measure these. However, the incremental costs associated with the incremental revenue generated from increased productivity are fairly low, since many of the costs of care for the average patient are fixed (overhead, personnel, space, equipment, etc).

\section{Limitations}

This study focused only on the productivity and financial aspects of using scribes in an outpatient clinical setting. We did not measure the effect of scribes on quality of care. This is very difficult to quantify. However, a number of physicians who used scribes commented on the opportunity (that resulted from increased available time provided by the scribes) to personally review tests (coronary angiograms, echocardiograms, etc) rather than simply reviewing test reports - and this could lead to improved quality of care. We did not measure patient satisfaction. However, our group ${ }^{1}$ and others ${ }^{23}$ have assessed patient satisfaction in the clinic and demonstrated neutral or beneficial effects, and improved physician-patient interaction ${ }^{1}$ using scribes, likely as a result of increased face-to-face interaction with patients during a clinic visit without distraction from interaction with a computer. We did not measure physician satisfaction. Physician burnout related to excessive workload, loss of autonomy, and excessive administrative work among other things is a major problem. . $^{210,11}$ The estimated 2.5 hours of time saved per full clinic day for our average physician using scribes may have an important impact on physician burnout and requires further study. Although coding level was higher for patients seen by physicians with scribes, we cannot prove that this was solely or predominantly due to the use of scribes. Our revenue calculations were estimates. The direct revenue measurements were accurate. The indirect revenue was defined as all CV revenue generated during the 2 months after a given clinic visit. While it is true that this methodology may overestimate some of the revenue (due to revenue accruing during this time frame not linked to the clinic visit), it may also underestimate the revenue associated with the clinic visit because it does not include tests ordered at the clinic visit to be performed outside the 2-month window, for example, prior to the next annual clinic visit.

\section{Conclusion}

We describe the impact of scribes on physician productivity and revenue in a large cardiology clinic over the course of a year. Physicians using scribes saw $\sim 10 \%$ more patients. This improved productivity resulted in 84 additional new patients and 423 additional follow-up patients seen, generating 3,029 additional wRVUs. The use of scribes resulted in an additional $\mathrm{CV}$ revenue of $\$ 1,372,694$ at a cost $<\$ 100,000$ for the scribes. We conclude that the use of medical scribes in a cardiology clinic results in substantial improvements in physician productivity and revenue generation at a relatively low cost.

\section{Acknowledgments}

The authors thank Janine Potter, Mark Turnbull, and Jaeda Roth for their assistance with data collection for this study.

\section{Disclosure}

Alan J Bank has received consulting fees from Scribe-X and Essia Health (medical scribe provider companies). The authors report no other conflicts of interest in this work.

\section{References}

1. Bank AJ, Obetz C, Konrardy A, et al. Impact of scribes on patient interaction, productivity, and revenue in a cardiology clinic: a prospective study. Clinicoecon Outcomes Res. 2013;5:399-406.

2. Dewa CS, Loong D, Bonato S, Thanh NX, Jacobs P. How does burnout affect physician productivity? A systematic literature review. BMC Health Serv Res. 2014;14:325.

3. Wood GC, Spahr R, Gerdes J, Daar ZS, Hutchison R, Stewart WF. Patient satisfaction and physician productivity: complementary or mutually exclusive? Am J Med Qual. 2009;24:498-504.

4. Hill RG, Sears LM, Melanson SW. 4000 clicks: a productivity analysis of electronic medical records in a community hospital ED. Am J Emerg Med. 2013;31:1591-1594.

5. Verdon DR. EHRs: the real story. Why a national outcry from physicians will shake the health information technology sector. Med Econ. 2014;91:18-20.

6. Bhargava HK, Mishra AN. Electronic Medical Records and Physician Productivity: Evidence from Panel Data Analysis. Available from: http:// dx.doi.org/10.2139/ssrn.1952287. Accessed November 1, 2011.

7. Gilchrist V, McCord G, Schrop SL, et al. Physician activities during time out of the examination room. Ann Fam Med. 2005;3:494-499.

8. Ritchie A. Primary care physicians seeing fewer patients. Med Econ. 2014;91:15-19.

9. Cocco G. Bureaucracy and medicine, an unholy marriage. Cardiovasc Med. 2012;15:243-244.

10. Shanafelt TD, Sloan JA, Habermann TM. The well-being of physicians. Am J Med. 2003;114:513-519. 
11. Shanafelt TD, Boone S, Tan L, et al. Burnout and satisfaction with work-life balance among US physicians relative to the general US population. Arch Intern Med. 2012;172:1377-1385.

12. Romeyke T, Stummer H. Clinical pathways as instruments for risk and cost management in hospitals - a discussion paper. Glob J Health Sci. 2012;4:50-59.

13. Venning P, Durie A, Roland M, Roberts C, Leese B. Randomized controlled trial comparing cost effectiveness of general practitioners and nurse practitioners in primary care. Br Med J. 2000;320:1048-1053.

14. Bauer JC. Nurse practitioners as an underutilized resource for health reform: evidence-based demonstrations of cost-effectiveness. $\mathrm{J} \mathrm{Am}$ Assoc Nurse Pract. 2010;22:228-231.

15. Litaker D, Mion L, Planavsky L, Kippes C, Mehta N, Frolkis J. Physician - nurse practitioner teams in chronic disease management: the impact on costs, clinical effectiveness, and patients' perception of care. J Interprof Care. 2003;17:223-237.

16. Arya R, Salovich DM, Ohman-Strickland P, Merlin MA. Impact of scribes on performance indicators in the emergency department. Acad Emerg Med. 2010;17:490-494.

17. DesRoches CM, Campbell EG, Rao SR, et al. Electronic health records in ambulatory care - a national survey of physicians. $N$ Engl J Med. 2008;359:50-60.
18. Poissant L, Pereira J, Tamblyn R, Kawasumi Y. The impact of electronic health records on time efficiency of physicians and nurses: a systematic review. J Am Med Inform Assoc. 2005;12:505-516.

19. Cheriff AD, Kapur AG, Qiu M, Cole CL. Physician productivity and the ambulatory EHR in a large academic multi-specialty physician group. Int J Med Inform. 2010;79:492-500.

20. De Leon S, Connelly-Flores A, Mostashari F, Shih SC. The business end of health information technology. Can a fully integrated electronic health record increase provider productivity in a large community practice? J Med Pract Manage. 2010;25:342-349.

21. Adler-Milstein J, Huckman RS. The impact of electronic health record use on physician productivity. Am J Manag Care. 2013;19:S345-S352.

22. Pizziferri L, Kittler AF, Volk LA, et al. Primary care physician time utilization before and after implementation of an electronic health record: a time-motion study. J Biomed Inform. 2005;38:176-188.

23. Koshy S, Feustel PJ, Hong M, Kogan BA. Scribes in an ambulatory urology practice: patient and physician satisfaction. J Urol. 2010;184 $258-262$.
ClinicoEconomics and Outcomes Research

\section{Publish your work in this journal}

ClinicoEconomics \& Outcomes Research is an international, peerreviewed open-access journal focusing on Health Technology Assessment, Pharmacoeconomics and Outcomes Research in the areas of diagnosis, medical devices, and clinical, surgical and pharmacological intervention. The economic impact of health policy and health systems

\section{Dovepress}

organization also constitute important areas of coverage. The manuscript management system is completely online and includes a very quick and fair peer-review system, which is all easy to use. Visit http://www.dovepress.com/testimonials.php to read real quotes from published authors. 